\title{
Knee alignment with and without implements in leg press and squat exercises: a systematic review
}

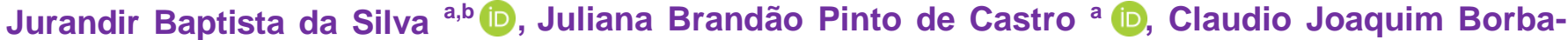 Pinheiro $^{b, c^{*}}$ D , Giovanne Moraes Ribeiro ${ }^{a}$ D, Danielli Braga de Mellod ${ }^{d}$, Rodrigo Gomes de Souza Vale $^{\mathrm{a}, \mathrm{e}}$ (iD)}

a Laboratório do Exercício e do Esporte (LABEES), Programa de Pós-Graduação em Ciências do Exercício e do Esporte, Universidade do Estado do Rio de Janeiro (UERJ), Rio de Janeiro-RJ, Brazil

b Universidade do Estado do Pará (UEPA) Campus XIII de Tucuruí-PA, Brazil

c Instituto Federal do Pará (IFPA) Campus de Tucuruí-PA, Brazil

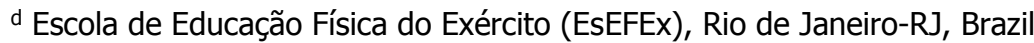

e Laboratório de Fisiologia do Exercício, Universidade Estácio de Sá, Cabo Frio-RJ, Brazil

*Corresponding author Ph: +55 94 98170-0066; Email: claudioborba18@gmail.com

DOI: https://doi.org/10.34256/ijpefs2121

Received: 25-02-2021, Revised: 01-04-2021; Accepted: 02-04-2021; Published: 04-04-2021

Abstract: Resistance training has been commonly used as a method of intervention in the rehabilitation of musculoskeletal injuries affecting the knee. Thus, the objective of this systematic review was to identify the methods employed with and without implements in leg press and squat exercises for the maintenance of knee alignment. The literature search was performed in the databases: PubMed, SciELO, and Lilacs. We used the descriptors "muscle strength" and "exercise" and their synonyms, available in the Health Sciences Descriptors (DeCS) and the Medical Subject Headings (MeSH), with the terms "valgus knee" and "varus knee". From the 1,117 articles found, eight studies were considered for the review. The included studies had samples composed of young men and women with advanced levels of training. Despite verifying conditions of valgus or varus knee, the studies presented different protocols and assessment methods. The implements comprised physioball, elastic resistance, and wedge. Electromyography and kinematics were used to assess muscle activity and movement patterns. These results reinforced the possibility of using implements to induce muscle and joint actions to reduce varus and valgus conditions. We suggest more studies to define the best strategies to reduce the excessive deviation of the patella in people who have valgus or varus knee.

Keywords: Resistance training, Leg Press, Squat, Knee, Muscle strength.

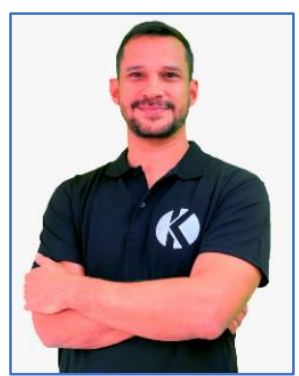

Mr. Jurandir Baptista da Silva is a Ph.D. student in Exercise and Sport Sciences from the Institute of Physical Education and Sports (IEFD), Rio de Janeiro State University (UERJ). Specialization in Biomechanics from the Federal University of Rio de Janeiro (UFRJ). Researcher at the Laboratory of Exercise and Sport (LABEES/UERJ). He is also an effective member of the Brazilian Society of Biomechanics and serving as a professor in Extension and Postgraduate courses in Brazil.

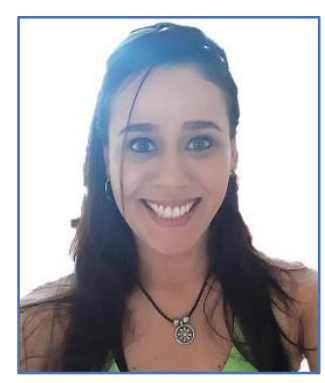

Dr. Juliana Brandão Pinto de Castro received Ph.D. in Exercise and Sport Sciences from the Institute of Physical Education and Sports (IEFD), Rio de Janeiro State University (UERJ). Master in Food, Nutrition, and Health from the Institute of Nutrition, UERJ. Graduated in Physical Education (licentiate and bachelor) from IEFD/UERJ. Researcher at the Laboratory of Exercise and Sport (LABEES/UERJ). Specialization in Higher Education Teaching (UCAM). Specialization in Geriatrics and Gerontology by the Faculty of Medical Sciences (FCM/UERJ). 


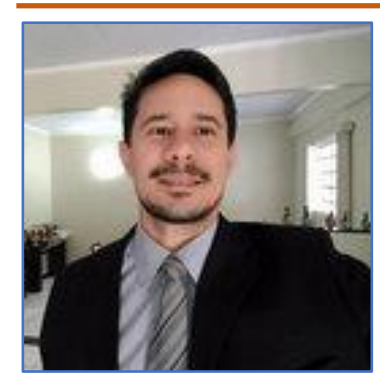

Dr. Claudio Joaquim Borba-Pinheiro obtained his Ph.D. in Science from the Federal University of the State of Rio de Janeiro (UNIRIO-RJ). Master in Human Motricity Sciences from the Castelo Branco University (UCB-RJ). Graduated in Physical Education from the Pará State University (UEPA-PA) with specialization in Judo (EsEFEx / UFRJ, 2001). Currently serving as a professor at the Federal Institute of Pará (IFPA) and the Pará State University (UEPA), both on the campuses of Tucuruí-PA, Brazil. Also, a coordinator of the Postgraduate Program Health in School Physical Education (UEPA-PA).

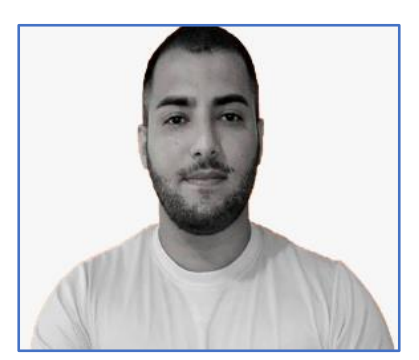

Mr. Giovanne Moraes Ribeiro completed his Master in Exercise and Sport Sciences from the Institute of Physical Education and Sports (IEFD), Rio de Janeiro State University (UERJ). Specialization in Strength Training and Functional Training from Castelo Branco University (UCB). Graduated in Physical Education from UCB.

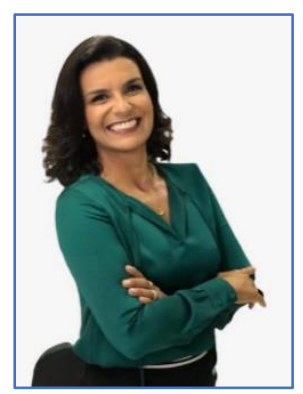

Dr. Danielli Braga de Mello received her Ph.D. in Public Health from Oswaldo Cruz Foundation (2008). Completed her PostDoctorate at Physiology in Extreme Environments from University of Portsmouth - UK (2016). Second Post-Doctorate in Thermography applied to Sport at the Polytechnic University of Madrid - ES (2019). Currently, she is serving as an Associate Professor at the Physical Education College of Brazilian Army (EsEFEx) and researcher at the Laboratory of Exercise and Sport (LABEES/UERJ). She is also a collaborating Professor at the Laboratory of Biosciences of Human Motricity (LABIMH/UNIRIO) and the Postgraduate Program in Exercise and Sport Sciences (PPGCEE/UERJ). She is the Co-Editor-in-Chief of the Journal of Physical Education (REF/JPE). Author of the book "Ciclismo Indoor".

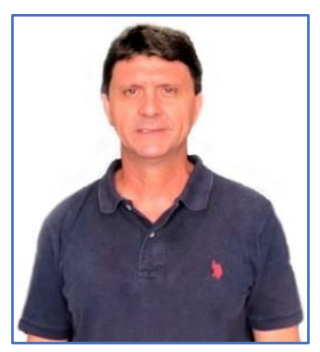

Dr. Rodrigo Gomes de Souza Vale Post-Doctorate in Biosciences from the Federal University of the State of Rio de Janeiro (UNIRIO). PhD in Health Sciences from Federal University of Rio Grande do Norte (UFRN). Master in Human Motricity
Science (UCB-RJ). Graduated in Physical Education (UFRJ). Adjunct Professor at the Institute of Physical Education and Sports (IEFD/UERJ). Coordinator of the Laboratory of Exercise and Sport (LABEES/UERJ). Professor at the Postgraduate Program in Exercise and Sport Sciences (PPGCEE/UERJ). Professor of the Physical Education and Physiotherapy course at Estacio de Sa University (UNESA-Cabo Frio/RJ). Coordinator of the Laboratory of Exercise Physiology (LAFIEX) and the Physical Education course at the Estacio de Sa University (UNESA-Cabo Frio/RJ).

\section{Introduction}

Strength, hypertrophy, and performance gains can be obtained by the adequate prescription of resistance training (RT) [1]. RT can also be an alternative intervention method in the rehabilitation of musculoskeletal injuries affecting the knee [2]. Excessive misalignment of the patella is a very frequent type of lesion in the RT, especially in the squat exercise, which may be, among other factors, influenced by the valgus knee or dynamic varus $[3,4]$.

The main causes of deviations in the knee joint have been frequently studied [5], among which we can highlight the dynamic stabilization of the knee, which is ensured by the musculature that surrounds this joint [4]. The hip directly influences the kinematics of the knee as well as other adjacent joints. The weakness of the gluteus medius is also described as an important factor in the dynamic valgus, because it causes the fall of the contralateral pelvis, increased internal rotation, and adduction of the lateral femur [6]. The gluteus medius is an important hip abductor and its strengthening is constantly described in the rehabilitation of musculoskeletal injuries, as in patellofemoral dysfunction. Its strengthening can generate a decrease in the dynamic valgus [7].

Another existing deformity, which is more frequent in women, is varus knee [8]. This is characterized when the resulting abnormal compressive load increases the contact stress on the lateral tibial plateau to the detriment of the reduction of the contact area on the lateral plateau. Such imbalance of forces causes overload in secondary knee stabilizers, capsule elongation, lateral collateral ligament, and iliotibial band [9]. The stretching and tensioning of this band lead to weakness of the lateral muscle group of the thigh and, consequently, the loss of lateral stability [10].

Different techniques have been used in RT to inhibit valgism and varism [11]. However, it is necessary to highlight through the literature the main 
findings regarding the RT on the stabilization of the knee joint and the respective methods used. Thus, this systematic review aimed to identify the methods employed with and without implements in leg press and squat exercises for the maintenance of knee alignment.

\section{Materials and Methods \\ 2.1 Study type}

This review was drafted based on the Preferred Reporting Items for Systematic Reviews and Meta-Analyses (PRISMA) recommendations [12].

\subsection{Inclusion criteria}

We included studies that addressed the use of implements, such as ball and elastic band, during the execution of exercises for lower limbs, such as leg press and squat, for strengthening and stabilization of the knee joint in healthy participants of both sexes aged between 18 to 40 years, written in English or Portuguese. We excluded articles that presented in their methodology evaluation protocols rather than intervention and with injured individuals in the sample.

\subsection{Search strategy}

Initially, we used the descriptors and their synonyms "muscle strength" and "exercise", available in the Health Sciences Descriptors (DeCS) and the Medical Subject Headings (MeSH), and the additional terms "valgus knee" and "varus knee". The search phrase was established using the Boolean operators [OR] (between synonyms) and [AND] (between descriptors). he searches were performed in the databases PubMed (US National Library of Medicine), SciELO (Scientific Electronic Library Online), and LILACS (Latin American and Caribbean Health Sciences Literature).

The search period was comprised between December 2018 and January 2021. The search strategy is presented in Table 1.

Following the inclusion criteria, the titles and abstracts were analyzed preliminarily, and those that were considered possibly eligible were recovered in their full version for a more accurate evaluation by two independent evaluators. The references of the original studies recovered were investigated to complement this review. When there was disagreement about the inclusion or exclusion of the article, a third independent evaluator was consulted.

\section{Results}

Of the 1,117 studies found through the search strategy, eight studies met the inclusion criteria of the present study. Figure 1 shows the selection process of the articles.

The characteristics of the participants in the included studies are summarized in Table 2. The total number of participants was 115 among men and women, although two studies did not specify the sex of the sample. The mean age of the participants ranged from 21 to 29 years.

Table 3 describes the procedural aspects, the objectives, exercises, implements used, evaluation instruments, and results of the studies that were reviewed. From the eight included studies, the leg press exercise was used in three $[4,13,14]$ and the other five performed the squat exercise [15-19].

Table 1 Search strategy

\begin{tabular}{lccc}
\hline Databases & Descriptors & Filters & $\begin{array}{c}\text { Electronic } \\
\text { addresses }\end{array}$ \\
\hline PubMed & $\begin{array}{c}\text { Muscle strength; resistance training; } \\
\text { strength training; exercise; knee; dynamic } \\
\text { valgus; dynamic varus; rehabilitation; hip } \\
\text { abduction muscles; hip; knee muscles; } \\
\text { quadriceps; Q angle; knee injury; elastic } \\
\text { band; physioball; squat; leg press; leg } \\
\text { exercise }\end{array}$ & $\begin{array}{c}\text { Title, } \\
\text { abstract }\end{array}$ & ncbi.nlm.nih.gov \\
\hline Lilacs & Valgus knee; varus knee; exercise; strength \\
training; knee & $\begin{array}{c}\text { Title, } \\
\text { abstract, } \\
\text { subject }\end{array}$ & pesquisa.bvsalud.org \\
\hline SciElo & Valgus knee; varus knee; exercise; strength & $\begin{array}{c}\text { Title, } \\
\text { abstract, } \\
\text { training; knee }\end{array}$ & seywords \\
\hline
\end{tabular}




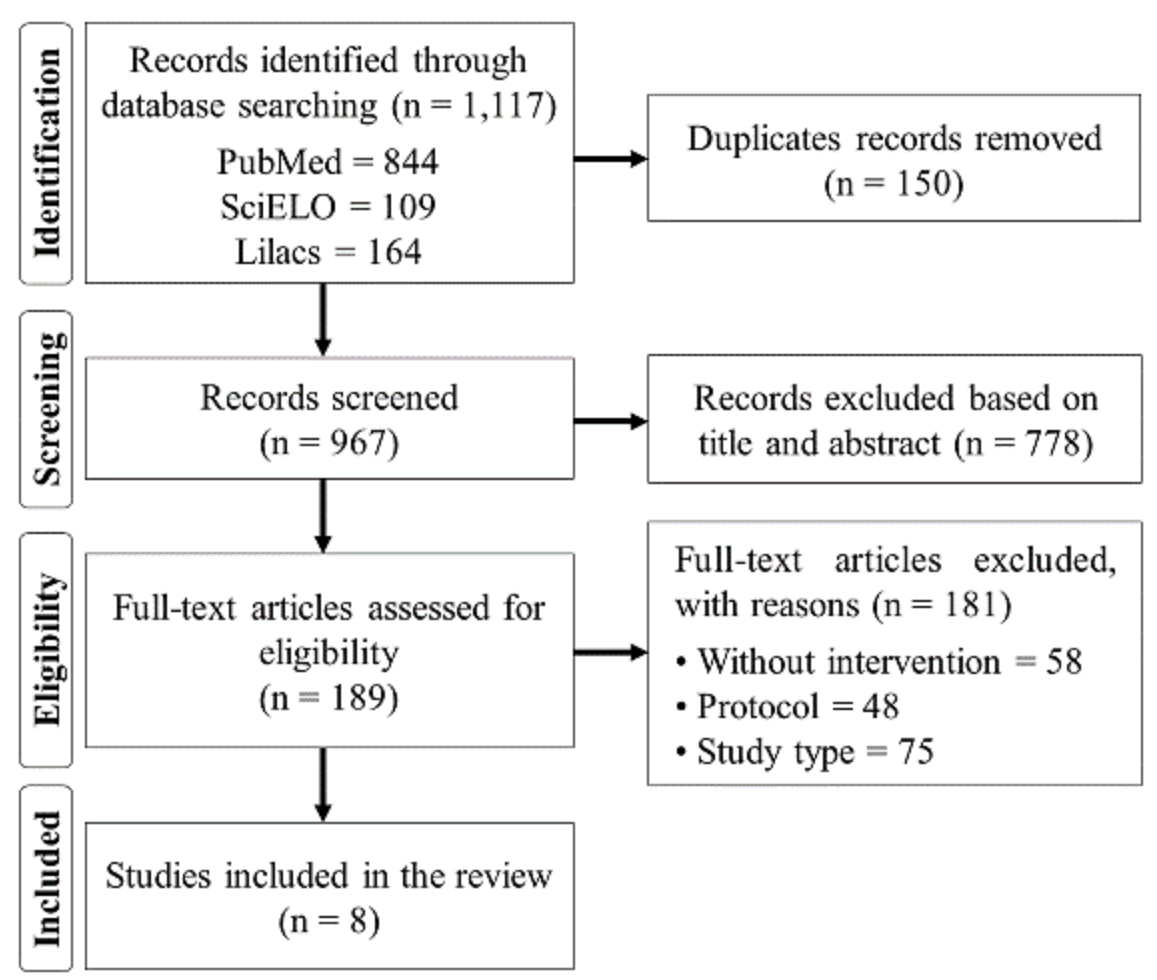

Figure 1 Flowchart of the selection process.

Table 2 Sample size, anthropometric characteristics, age, and training level of the participants included in the studies.

\begin{tabular}{|c|c|c|c|c|c|}
\hline Study & $\begin{array}{c}\text { Sample } \\
\text { (n and sex) }\end{array}$ & $\begin{array}{l}\text { Age } \\
\text { (years) }\end{array}$ & $\begin{array}{c}\text { Body mass } \\
(\mathrm{kg})\end{array}$ & $\begin{array}{c}\text { Height } \\
(\mathrm{cm})\end{array}$ & $\begin{array}{c}\text { Physical } \\
\text { Activity Level }\end{array}$ \\
\hline Paz et al. [4] & $8 W$ & $24.4 \pm 2.1$ & $65.1 \pm 4.4$ & $168.1 \pm 4$ & Trained \\
\hline $\begin{array}{l}\text { Araujo and } \\
\text { Silva Junior } \\
{[13]}\end{array}$ & $14 \mathrm{~W}$ & $29.3 \pm 7.5$ & $84.1 \pm 11.8$ & NR & Advanced level \\
\hline $\begin{array}{l}\text { Claiborne et al. } \\
\text { [14] }\end{array}$ & $\begin{array}{c}30 \\
(15 \mathrm{M} \text { and } 15 \\
\mathrm{W})\end{array}$ & $\begin{array}{l}M: 26.4 \pm 5.2 \\
W: 23.5 \pm 3.7\end{array}$ & $\begin{array}{l}M: 84.1 \pm 11.8 \\
W: 66.0 \pm 5.6\end{array}$ & $\begin{array}{l}\text { M: } 176.9 \pm 7.1 \\
\text { W: } 170.9 \pm 9.5\end{array}$ & NR \\
\hline $\begin{array}{l}\text { Foley et al. } \\
{[15]}\end{array}$ & $16 \mathrm{M}$ & $\begin{array}{l}\mathrm{T}: 25.4 \pm 4.4 \\
\mathrm{U}: 22.8 \pm 1.6\end{array}$ & $\begin{array}{l}\mathrm{T}: 88.3 \pm 12.5 \\
\mathrm{U}: 76.9 \pm 9.2\end{array}$ & $\begin{array}{l}\text { T: } 179.8 \pm 8.8 \\
\text { U: } 180.8 \pm 6.0\end{array}$ & $\mathrm{~T}$ and $\mathrm{U}$ \\
\hline Lee et al. [16] & 20 (NR) & $21.5 \pm 1.1$ & $57.95 \pm 8.44$ & $166.85 \pm 9.26$ & NR \\
\hline $\begin{array}{l}\text { Peng et al. } \\
{[17]}\end{array}$ & $10 \mathrm{M}$ & $21.0 \pm 1.4$ & $70.8 \pm 9.0$ & $174.4 \pm 7.1$ & Advanced level \\
\hline $\begin{array}{l}\text { Forman et al. } \\
\text { [18] }\end{array}$ & 7 (NR) & $23.9 \pm 2.4$ & $86.8 \pm 14.7$ & $178.8 \pm 9.4$ & Trained \\
\hline Silva et al. [19] & $10 \mathrm{M}$ & NR & $63.86 \pm 6.02$ & $172 \pm 0.06$ & Trained \\
\hline
\end{tabular}


Table 3 Methodological characteristics of the included studies

\begin{tabular}{|c|c|c|c|c|}
\hline Study & $\begin{array}{l}\text { Exercise / } \\
\text { Implemen } \\
\text { ts }\end{array}$ & $\begin{array}{l}\text { Instrument } \\
\mathrm{s}\end{array}$ & Procedures & Results \\
\hline $\begin{array}{l}\text { Paz et } \\
\text { al. [4] }\end{array}$ & $\begin{array}{l}\text { Leg } 45^{\circ} \\
\text { (Physioball } \\
\text { and EB) }\end{array}$ & $\begin{array}{l}\text { EMG } \\
\text { BF, VL, VMO, } \\
\text { RF }\end{array}$ & $\begin{array}{l}4 \text { sets with } 70 \% \text { of } \\
10 \text { RMS for each } \\
\text { protocol: } \\
\text { Control Physioball; } \\
\text { EB }\end{array}$ & $\begin{array}{l}\uparrow \mathrm{C}_{\mathrm{RMS}} \text { level of } \mathrm{BF}, \mathrm{VL} \text {, and } \mathrm{VMO} \text { when } \\
\text { they used physioball and } \mathrm{EB}\end{array}$ \\
\hline $\begin{array}{l}\text { Araujo } \\
\text { and } \\
\text { Silva } \\
\text { Junior } \\
\text { [13] }\end{array}$ & $\begin{array}{l}\text { Leg } 45^{\circ} \text { and } \\
\text { extensive } \\
\text { chair }(E C)\end{array}$ & $\begin{array}{l}\text { Goniometer, } \\
\text { 3D analysis }\end{array}$ & NR & $\begin{array}{l}\text { Angle } Q \text {, when compared in } \mathrm{LP} \text { and } \mathrm{EC} \text {, } \\
\text { changed with the increase } \\
\text { Knee flexion, both for normal knees and } \\
\text { for valgus }\end{array}$ \\
\hline $\begin{array}{l}\text { Claiborn } \\
\text { e et al. } \\
{[14]}\end{array}$ & $\begin{array}{l}\text { Single leg } \\
\text { squat }\end{array}$ & $\begin{array}{l}\text { 3D analysis } \\
\text { of the frontal } \\
\text { plane of the } \\
\text { knee }\end{array}$ & $\begin{array}{l}\text { S1: squat with } 60^{\circ} \\
\text { of knee flexion and } \\
\text { return to standing } \\
\text { position; } \\
\text { S2: Isokinetic, } \\
\text { concentric and } \\
\text { eccentric (hip } \\
\text { abduction/adductio } \\
\mathrm{n} \text {; knee } \\
\text { flexion/extension) }\end{array}$ & $\begin{array}{lrr}\text { Significant relationship } & \text { between } \\
\text { flexor/extensor/adductor/hip } & \text { rotator, } \\
\text { knee flexor, extensor strength } & \end{array}$ \\
\hline $\begin{array}{l}\text { Foley et } \\
\text { al. [15] }\end{array}$ & $\begin{array}{l}\text { Free } \\
\text { squatting } \\
\text { with the bar } \\
\text { on the } \\
\text { back/ EB }\end{array}$ & $\begin{array}{l}\text { 3D analysis, } \\
\text { medial } \\
\text { collapse of } \\
\text { knee, and } \\
\text { EMG of } \\
\text { GMa, GMe, } \\
\text { VL, BF }\end{array}$ & $\begin{array}{lr}\text { Trained } & \text { group, } \\
\text { performed } & \text { 3RM. } \\
\text { Untrained group, } & \text { gril } \\
\text { repetitions } & \text { until } \\
\text { failure } & \text { with } \\
\text { bodyweight } & \end{array}$ & $\begin{array}{l}\text { During 3RM, the weight of the squat } \\
\text { was not affected by the intervention of } \\
\text { the EB. The trained group had a greater } \\
\text { amplitude regardless of the band. } \\
\text { During concentric phase, knee width } \\
\text { index was significantly lower for 3RM } \\
\text { squats }\end{array}$ \\
\hline $\begin{array}{l}\text { Lee } e t \\
\text { al. [16] }\end{array}$ & $\begin{array}{l}\text { Squat } \\
\text { free/ball } \\
\text { between } \\
\text { knees, EB, } \\
\text { and wedge } \\
\text { beneath the } \\
\text { feet }\end{array}$ & $\begin{array}{l}\text { EMG } \\
\text { VL and VMO }\end{array}$ & NR & $\begin{array}{l}\text { VMO EMG using wedge below the feet } \\
>\mathrm{B} \text {. E } \\
\text { VMO EMG in conventional squat and } \\
\text { with the wedge }>\text { than when they used } \\
\text { the ball }\end{array}$ \\
\hline $\begin{array}{l}\text { Peng et } \\
\text { al. [17] }\end{array}$ & $\begin{array}{l}\text { LP / } \\
\text { Medicine } \\
\text { ball }\end{array}$ & $\begin{array}{l}\text { EMG } \\
\text { VMO, VL, } \\
\text { and } A L \text { of the } \\
\text { dominant } \\
\text { limb }\end{array}$ & $\begin{array}{l}\text { LP in } 3 \text { conditions: } \\
\text { TLP, LPSM, and } \\
\text { LPM using a } \\
\text { medicine ball of } \\
6 \mathrm{~kg} \text {. Concentric } \\
\text { and eccentric }\end{array}$ & $\begin{array}{l}\text { Motion angle, small to medium effect } \\
\text { size was observed incorporating the } \\
\text { isometric adduction of the hip during } \\
\text { the LP as the VMO/VL ratio }\end{array}$ \\
\hline $\begin{array}{l}\text { Forman } \\
\text { et al. } \\
{[18]}\end{array}$ & $\begin{array}{l}\text { Free Squat } \\
\text { with the bar } \\
\text { above the } \\
\text { head } \\
\text { (OHS). EB }\end{array}$ & $\begin{array}{l}\text { 3D analysis } \\
\text { Bending } \\
\text { angle } \\
\text { EMG } \\
\text { of the } \\
\text { muscles: } \\
\text { AT, VMO RF, } \\
\text { VL, GMa, } \\
\text { GMe }\end{array}$ & $\begin{array}{l}\text { Each participant } \\
\text { performed } 1 \text { set of } \\
12 \text { reps with EB in } \\
\text { the knee and } \\
\text { without EB in the } \\
\text { knee }\end{array}$ & $\begin{array}{l}\text { Knee flexion angle was higher when } \\
\text { performed without EB. Mean knee width } \\
\text { index (IL) was higher in the squat } \\
\text { without EB, as well as the maximum IL. } \\
\text { There was no difference between } \\
\text { protocols }\end{array}$ \\
\hline $\begin{array}{l}\text { Silva et } \\
\text { al. [19] }\end{array}$ & $\begin{array}{l}\text { Squat } \\
\text { exercise } \\
\text { (physioball } \\
\text { and EB) }\end{array}$ & $\begin{array}{l}\text { EMG } \\
\text { VMO, VL, RF, } \\
\text { BF }\end{array}$ & $\begin{array}{l}\text { Three protocols } \\
\text { with the intensity } \\
\text { of } 50 \text { and } 100 \% \text { of } \\
\text { 10RM without the }\end{array}$ & $\begin{array}{l}\text { The distance between knees in the } \\
\text { control protocol was lower when } \\
\text { compared to SI } 50 \% \text {, with SI } 100 \% \text { and } \\
\text { with EB } 100 \% \text {. The distance between }\end{array}$ \\
\hline
\end{tabular}


use of implements

(SI) and with the use the knees was also lower for the protocols physioball $100 \%$ and EB $100 \%$ compared to the SI $100 \%$ protocols. VMO presented greater activation in the SI $50 \%$ protocols and physioball $50 \%$ when compared to the EB 50\% protocol

BF: biceps femoris; VL: vastus lateralis; VMO: vastus medialis oblique; RF: rectus femoris; $A T$ = anterior tibial; GA: gastrocnemius; GMa: gluteus maximus; GMe: gluteus medius; RMS: average value of normalized square root; EB: elastic band; $C_{R M S}$ : coefficient of root mean square; EMG = electromyography; S: session; VL = vastus lateralis; LP: leg press; TLP: traditional leg press; LPSM: LP with submaximal isometric action; LPM: LP with maximal isometric action; TUT: time under tension; RM: repetition maximum; reps: repetitions; NR: not reported.

\section{Discussion}

This systematic review was to identify the methods employed with and without implements in leg press and squat exercises for the maintenance of knee alignment. The included studies [4,13-19] showed samples composed of young men and women with advanced levels of training. Despite verifying conditions of valgus or varus knee, the studies presented different protocols and assessment methods. All studies aimed to verify methods and implements that could help the muscles responsible for stabilizing the knee to avoid valgus and varus conditions. The implements used in the reviewed studies were physioball, elastic resistance, and wedge. Electromyography and kinematics were used as a technique for assessing muscle activity and movement patterns.

The leg press exercise was used in three reviewed studies $[4,13,14]$. In the study by Paz et al. [4], the objective was to investigate the performance during the RT performing the leg $45^{\circ}$ exercise using physioball and elastic band in 4 sets of 10 repetitions maximum (RM) for each protocol. Peng et al. [17] analyzed the effects of the leg press (LP) exercise in 3 conditions: traditional LP, LP with submaximal isometric action (LPSM), and LP with maximal isometric action (LPM) using a medicine ball. In the study carried out by Araujo and Silva Junior [13], the authors analyzed the $\mathrm{Q}$ angle of the knee by analyzing the kinematics in 3 dimensions (3D) and the knee flexion angle through the goniometer when performing the exercise in just one protocol without external overload.

The five studies that analyzed the squat exercise also used different protocols [15-19]. Foley et al. [15] evaluated the effects of the elastic band on kinematics and muscle activity during free squat with the barbell.
3D analysis was used as a method of evaluating movement and electromyography to analyze electrical activity. To investigate the effect of the free squat exercise, Lee et al. [16] used intervention protocols such as elastic band, physioball, and wedge below the feet. Forman et al. [18] and Foley et al. [15] used free squatting with the bar on the back and the elastic band. Silva et al. [19] used three protocols with the intensity of 50 and $100 \%$ of $10 \mathrm{RM}$ with physioball and elastic band and without the use implements.

Despite not using implements during exercises, two studies aimed to verify the stabilization of the knee $[13,14]$. In the study by Araujo and Silva Junior [13], the authors analyzed the $\mathrm{Q}$ angle of the knee during the leg press and the extensor chair. In their results, the $\mathrm{Q}$ angle, when compared to the two exercises, changed with the increase in knee flexion, both for normal and valgus knees. Claiborne et al. [14] used 3D analysis of the frontal plane of the knee to determine the relationship between the strength of the hip and the knee and the movement of the valgus knee during the squat exercise. As a result, they found a negative relationship between the maximum isokinetic torque of the hip abductors and the external rotators during movement. They also found a significant relationship between the hip flexor, hip extensor, hip adductor, internal hip rotator, knee flexor, knee extensor strength, and knee valgus position.

These results reinforced the possibility of using implements to induce muscle and joint actions to reduce varus and valgus conditions. Thus, six studies used implements to check possible influences on the movement pattern to reduce these conditions and possible changes in muscle activity. Paz et al. [4] found high levels of mean square root in $\mathrm{BF}, \mathrm{VL}$, and $\mathrm{VMO}$ coefficients (CRMS) when they used the physioball 
implements and elastic band compared to the control protocol without implement. The authors concluded that the procedures performed can be good alternatives to reduce these deviations and stabilize the knee. The results by Paz et al. [4] differs from Peng et al. [17], who analyzed the effects of the leg press exercise (LP) under 3 conditions: traditional LP, LP with submaximal isometric action (LPSM), and LP with maximum isometric action (LPM) using a $6 \mathrm{~kg}$ medicine ball. Regarding the angle of movement, when incorporating the isometric adduction of the hip during $L P$, the size of the effect observed from the VMO/VL activation ratio was shown to be small to medium.

However, the results by Lee et al. [16] are aligned with the findings of Paz et al. [4] and misaligned with the results of Peng et al. [17]. In their investigation, when evaluating intervention protocols such as elastic band, physioball, and wedge below the feet, the authors did not find significant differences between the exercises compared to the activity of the vastus lateralis muscle. In the wedge squat exercise, significantly greater activity of the vastus medialis oblique muscle was found compared to the squat exercise with elastic band. The authors suggest that conventional squat exercise may be one of the useful interventions for patients with patellofemoral pain syndrome. These different results can be explained by the use of different exercises with different intensities and training levels.

Following this reasoning, different intensities were assessed by Foley et al. [15] when evaluating the effects of the elastic band on kinematics and muscle activity during free squats with the back bar in two intensities divided into trained and untrained subjects. The trained group performed 3RM, while the group of untrained individuals performed repetitions with bodyweight until failure. During 3RM, the squat weight was not affected by the intervention of the elastic band. The trained group had a greater range regardless of the band. During the concentric phase, the index of spacing between the knees was significantly lower for 3RM squats.

Silva et al. [19] also verified different intensities, however, the authors also compared the protocols without the use of implements, with the use of a ball and elastic band and with the static position (control). A shorter distance between the knees was verified for the control protocol compared to the implement without $50 \%$ and $100 \%$ of the maximum strength and $100 \%$ elastic. These results reinforce the condition of dynamic varus in the performance of the exercise in these protocols. The protocol without implements $50 \%$ also showed a significant difference, being greater in relation to the ball protocols $50 \%$ and elastic $50 \%$. There was also a difference in the protocol without an implement with an intensity of $100 \%$ with the protocols, ball $100 \%$ and elastic $100 \%$ $(p<0.001)$, these being with a shorter distance between the knees, demonstrating that both protocols were able to reduce the dynamic varus. Although both showed a reduction in the dynamic varus, the $100 \%$ ball protocol reduced the distance between the knees more than the $100 \%$ elastic protocol.

The limitations of the present systematic review were the lack of clarifications regarding procedural protocols and training level of participants in some studies. Another point not reported in the studies listed was the familiarization process of the participants with the exercises proposed in the investigations performed. The application of familiarization can reduce the errors associated with the learning effects, as well as its absence can interfere with the quality of the results obtained [4]. Moreover, we only used three electronic databases in our search. Although PubMed, SciELO, and Lilacs catalog a great number of scientific journals worldwide, it may be that some studies published in other journals not indexed in these databases were not included in this review.

\section{Conclusion}

From the revised studies, there was a high vulnerability of the methods applied for training aimed at strengthening and stabilizing the knee. Clarification was lacking regarding procedural protocols, level of training, and familiarization of participants with the protocols used. Thus, these studies may be considered insufficient to define the best strategies to reduce the excessive deviation of the patella in people with valgus or varus knee. Thus, it is opportune to carry out further studies to analyze the use of implements such as physioball and elastic band, verifying, in addition to muscular activation, variables such as time under tension and knee alignment in protocols with different intensities and volume of execution of the analyzed exercises.

\section{References}

[1] E.R. Monteiro, L.B. De Melo, T.G. Gomes, I.B.F. Dias, G.A. Paz, B.F. De Salles, H.L. Miranda, Efeito da ordem de execução de 
séries alternadas por segmento comparadas a séries tradicionais sobre o desempenho de repetições máximas em diferentes segmentos corporais, Revista Brasileira de Prescrição e Fisiologia do Exercício, 9(55) (2016) 519-525.

[2] A.E. Capote, S.A.M. Knaut, R.M. Magnani, W. Vilas, B. Fernande, L.J. Carneiro, M.H. Takemoto, Análise da ativação neuromuscular do vasto medial oblíquo e vasto lateral com o uso da bandagem functional, Acta Fisiátrica, 21(1) (2014) 11-5. [DOI]

[3] Maria Célia Cunha Ciaccia, Camila Nazareth Pinto, Fernanda da Costa Golfieri, Tales Ferreira Machado, Lívia Lopes Lozano, João Marcel Sanseverino Silva, Vera Esteves Vagnozzi Rullo, Prevalência de genuvalgo em escolas públicas do ensino fundamental na cidade de Santos (SP), Brasil, Revista Paulista de Pediatria, 35(4) (2017) 443-7. [DOI]

[4] G.A. Paz, J. Freitas, M.F. Maia, J. Silva, V. Lima, H. Miranda, Electromyography activation of the lower-limb muscles adopting a physioball and elastic band to stabilize the knee joint during multiple sets with submaximal loads, Journal of Sport Rehabilitation, 26(5) (2017) 406-14. [DOI] [PubMed]

[5] V. Roque, I. Macedo, I. Rocha, I. Barroso, Patellofemoral syndrome, Revista da Sociedade Portuguesa de Medicina Física e de Reabilitação, 22(3) (2012) 53-61.

[6] T.H. Nakagawa, T.B. Muniz, R.M. de Baldon, F.V. Serrão, A abordagem funcional dos músculos do quadril no tratamento da syndrome, Fisioterapia em Movimento, 21(1) (2008) 65-72.

[7] B.L. Heinert, T.W. Kernozek, J.F. Greany, D.C. Fater, Hip abductor weakness and lower extremity kinematics during running, Journal of Sport Rehabilitation, 17(3) (2008) 243-56. [DOI] [PubMed]

[8] R.M. Baldon, D.F.M. Lobato, L.P. Carvalho, P.Y.L. Wun, F.V. Serrão, Diferenças biomecânicas entre os gêneros e sua importância nas lesões do joelho, Fisioterapia em Movimento, 24(1) (2011) 157-66. [DOI]

[9] F.R. Noyes, S.D. Barber-Westin, C. Fleckenstein, C. Walsh, J. West, The dropjump screening test: difference in lower limb control by gender and effect of neuromuscular training in female athletes, The American
Journal of Sports Medicine, 33(2) (2005) 197207. [DOI] [PubMed]

[10] M. Nordin, V.H. Frankel, Biomecânica básica do sistema musculoesquelético. 4. ed. Rio de Janeiro: Guanabara Koogan; 2014.

[11] C-Y. Song, Y-F. Lin, T-C. Wei, D-H. Lin, T-Y. Yen, $\mathrm{M}-\mathrm{H}$. Jan, Surplus value of hip adduction in leg-press exercise in patients with patellofemoral pain syndrome: a randomized controlled trial, Physical Therapy, 89(5) (2009) 409-18. [DOI] [PubMed]

[12] Alessandro Liberati, Douglas G Altman, Jennifer Tetzlaff, Cynthia Mulrow, Peter C Gøtzsche, John P A Ioannidis, Mike Clarke, P J Devereaux, Jos Kleijnen, David Moher, The PRISMA statement for reporting systematic reviews and meta-analyses of studies that evaluate healthcare interventions, BMJ, 339 (2009) b2700. [DOI]

[13] A.J.S. Araujo, W.M. Silva Junior, The $Q$ angle analysis, during resistance training, on open kinematics chain and intermidiate closed kinematics chain, through photogrammetry, Revista Brasileira de Ciências do Esporte, 36(2) (2014) 327-39. [DOI]

[14] T.L. Claiborne, C.W. Armstrong, V. Gandhi, DM. Pincivero, Relationship between hip and knee strength and knee valgus during a single leg squat, Journal of Applied Biomechanics, 22(1) (2006) 41-50. [DOI] [PubMed]

[15] R.C. Foley, B.D. Bulbrook, D.C. Button, M.W. Holmes, Effects of a band loop on lower extremity muscle activity and kinematics during the barbell squat, International Journal of Sports Physical Therapy, 12(4) (2017) 55059. [PubMed]

[16] T-k. Lee, S-m. Park, S-b. Yun, A-r. Lee, Y-s. Lee, M-s. Yong, Analysis of vastus lateralis and vastus medialis oblique muscle activation during squat exercise with and without a variety of tools in normal adults, Journal of Physical Therapy Science, 28(3) (2016) 10713.

[17] H-T. Peng, T.W. Kernozek, C-Y. Song, Muscle activation of vastus medialis obliquus and vastus lateralis during a dynamic leg press exercise with and without isometric hip adduction, Physical Therapy in Sport, 14(1) (2013) 44-9. [DOI] [PubMed]

[18] D.A. Forman, G.N. Forman, D.C. Button, M.W. Holmes, Theraband $\AA$ CLX gold reduces kneewidth index and range of motion during 
overhead, barbell squatting, Sports

Biomechanics, 20(2) (2021) 198-212. [DOI] [PubMed]

[19] Jurandir Baptista da Silva, Giovanne Moraes Ribeiro, Danielli Braga de Mello, Rodolfo de Alkmim Nunes, Guilherme Rosa, Vicente Lima, Rodrigo Gomes de Souza Vale, Análise do exercício agachamento com e sem o uso de physioball e banda elástica em diferentes intensidades, Journal of Physical Education, 31 (2020) e3171. [DOI]

\title{
Funding
}

No funding was received to carry out this study

\begin{abstract}
Authors Contribution
Jurandir Baptista da Silvaa - Study design, methodology \& wrote the paper; Juliana Brandão Pinto de Castro - Study design, methodology \& wrote the paper; Claudio Joaquim Borba-Pinheiro - Designed the study and analysis, contributed to the data analysis, Supervision, Edited the manuscript; Giovanne Moraes Ribeiro - Study design, methodology \& wrote the paper; Danielli Braga de Mello Study design, methodology \& wrote the paper; Rodrigo Gomes de Souza Vale - Study design, methodology \& wrote the paper. All the authors read and approved the final copy of the manuscript.
\end{abstract}

Does this article screened for similarity?

Yes.

Conflict of interest

The authors have no conflicts of interest to declare that they are relevant to the content of this article.

\section{About The License}

(C) The Author(s) 2021. The text of this article is open access and licensed under a Creative Commons Attribution 4.0 International License 